\title{
57
}

\section{Enterprise modeling and integration in Mexican manufacturing and service companies}

\author{
Arturo Molina and Angel Arriaga \\ CSIM - ITESM \\ Ave. Eugenio Garza Sada 2501 Sur \\ Monterrey, N.L. 64849 MEXICO \\ e-mail:armolina@campus.mty.itesm.mx
}

\begin{abstract}
This paper describes the result of an assessment study carried out to analyse the use of enterprise modelling in Mexican micro, small, medium, and large companies to achieve Enterprise Integration. An assessment tool was developed based on a questionnaire on how Strategic Planning, Technology Planning and Technology Integration is performed and what models and methodologies are used in Mexican companies. The study has been undertaken in 32 manufacturing/services companies. The results of the exploratory exercise where: medium companies, on average, are the more integrated enterprises, large companies do a lot of strategic planning but they have problems in implementing and integrating technology, finally micro-companies are not aware of the need for enterprise integration.
\end{abstract}

Keywords

Assessment Tool, Enterprise Integration, Strategic Planning, Technology Planning, Technology Integration

\section{INTRODUCTION}

New concepts such as enterprise integration and modeling have been recognized to be key for the successful alignment of strategies and technologies within a company. However, not all the stages of a complete master plan for the integration 
of enterprise are carried out by all companies, because master plans take a lot of effort to be developed and long time to be implemented. The objective of this research carried out in micro, small and medium, large Mexican manufacturing and service companies was to identify how companies are integrating technologies accordingly to the company's strategic plans. The study was carried out in 32 companies belonging to the service and manufacturing sectors. A key issue of the research was to analyze what companies are doing to define technological strategic plans and what actions are being undertaken to design and implement integrated information systems to achieve the defined strategies. Based on these results it was possible to recognize the areas of opportunity for the introduction of enterprise integration and modeling concepts to formalize the process of implementing technological strategies. A program has been defined to support the application of enterprise integration concepts in small and medium enterprises (SMEs).

\section{SCOPE OF THE RESEARCH STUDY}

The study was carried out in two neighbouring states in the north part of Mexico (Nuevo Leon and Coahuila) in the cities of Monterrey and Saltillo. The study included a total of 32 micro, small \& medium, and large manufacturing and services companies, subdivided accordingly to the number of employees (Table 1). The service companies which participated in the study were software, insurance, and finance companies. Manufacturing companies were from the plastic, metalmechanic and automotive sectors. These type of companies were selected because they represent sectors of major importance in this region.

Companies were selected randomly. The subjects interviewed were CIO's and Planning Managers in large and medium companies, where this position exists. In small and micro companies the subjects interviewed were General Managers, Directors or Owners.

Table 1 Number of Services and Manufacturing Companies interviewed

\begin{tabular}{llll}
\hline & $\begin{array}{l}\text { Micro companies } \\
\text { 1-15 employees }\end{array}$ & $\begin{array}{l}\text { SMEs } \\
16-250 \text { employees }\end{array}$ & $\begin{array}{l}\text { Large companies } \\
\text { more than 250 } \\
\text { employees }\end{array}$ \\
\hline Services & 7 & 5 & 4 \\
Manufacturing & 5 & 5 & 6 \\
TOTAL & 12 & 10 & 10 \\
\hline
\end{tabular}




\section{ASSESSMENT TOOL FOR ENTERPRISE INTEGRATION}

The assessment tools was designed as an interview of 55 questions based on what PERA (Williams 1991) and GERAM methodology (Bernus and Nemes 1994) have defined as the underlying methodology for enterprise integration.

Major challenge in the design of the questionnaire was to map the concepts defined in the Life Cycle of an Enterprise (Identification, Concept, Requirements, Design, Operation, Decommission) to concepts used by industry such as strategic planning, system design, system implementation and operation, etc. Therefore the questionnaire was divided in three parts: Strategic Planning, Technology Planning, and Technology Integration and Implementation.

The section related to Strategic Planning aimed to identify general questions regarding the identification phase for the preparation of Enterprise Integration Plans (e.g. establishment of the initial program, champion identification, getting management support, and steering committee definition); it also has questions regarding the identification of the enterprise business entity (EBE); and definition and documentation of the enterprise strategic plans (e.g. mission, vision and company values, objectives, strategies, goals, business plans, critical success factors and policies).

The second part, defined as Technology Planning, was concerned with the requirements phase, the identification and building of the enterprise integration planning team; general EBE process description; identification of initiatives and opportunities; As-Is definition of the human and organisational architecture, information systems architecture, and manufacturing and service equipment architecture; To-Be definition of the three architectures; development of a transition plan; identification of the required standards selection process; identification of logical transition path from As-Is to To-Be; development of training and education plan; identification of feasible solutions in the form of a set of enterprise integration projects; and the analysis of costs, benefits and risks for the proposed integration program.

The last part of the questionnaire, defined as Technology Integration and Implementation, was related to the design phase which contains the identification and analysis of the requirements of the human and organisational architecture, information systems architecture, and of the customer product or service equipment architecture to attain the To-Be model proposed; the detailed design of solutions about the personnel skills development, organisational planning, and training programs development in the human and organisational architecture; the detailed design of solutions about the equipment selection and systems layout in the information systems architecture; and the detailed design of the required equipment in the customer product or service equipment architecture. The final questions were regarding to the implemented vs. planned programmes; final evaluation, dissemination and feedback of the master plan; and the creation of 
continuous education and training plan. There were no questions regarding the operation or decommission of technology.

The questionnaire also included three open questions about methodologies used to:

- Analyse and describe the business process.

- Manage and control the integration program.

- Manage and integrate information systems.

These open questions were included to find out if there were already in use modelling methodologies for Enterprise Integration.

\section{RESULTS OF THE RESEARCH STUDY}

The analysis of the data collected was carried out in three ways:

1. Obtain percentages to see the tendency of how Enterprise Integration concepts are being achieved.

2. Create polar graphics to determine the areas of opportunity to introduce Enterprise Integration and Modelling.

3. Determine different methodologies used to manage, design and implement Enterprise Integration Programmes.

In the next subsections discussions of the findings are presented.

\subsection{Enterprise Integration Concepts Realization}

Strategic planning is not a common practice in micro companies, as only half of them have a certain form of strategic planning. However micro manufacturers are more aware of the importance of strategic planning than the services companies. In Table 2 the percentage of use of enterprise concepts in manufacturing micro companies is larger than in service companies. Small, Medium and Large service companies are practising more strategic planning than manufacturing enterprises, the reason of this is the strong competition that services companies are facing nowadays in Mexico. Manufacturing companies are more concentrated in every day operation activities. Nevertheless not all SMEs have formalised the use of strategic planning, and even if they do have it, due to changes in the competitive environment they usually ignored it in practice. 
Table 2 Enterprise Integration Concepts Realisation

\begin{tabular}{llll}
\hline & $\begin{array}{l}\text { Strategic } \\
\text { Planning }\end{array}$ & $\begin{array}{l}\text { Technology } \\
\text { Planning }\end{array}$ & $\begin{array}{l}\text { Technology } \\
\text { Integration and } \\
\text { Implementation }\end{array}$ \\
\hline Micro-services companies & $49 \%$ & $48 \%$ & $29 \%$ \\
Micro-manufacturing companies & $55 \%$ & $59 \%$ & $52 \%$ \\
Middle-services companies & $92 \%$ & $92 \%$ & $83 \%$ \\
Middle-manufacturing & $88 \%$ & $77 \%$ & $82 \%$ \\
companies & & & \\
Large-services companies & $97 \%$ & $92 \%$ & $87 \%$ \\
Large-manufacturing companies & $89 \%$ & $87 \%$ & $87 \%$ \\
\hline
\end{tabular}

Related to technology planning, service micro companies are not interested in technology planning. Nevertheless, micro manufacturing firms are worried about what technology to use to improve their production and therefore technology planning is part of their vocabulary, as it represents a major investment. Services SMEs are concentrating their efforts to plan what technology is needed to improve their services. For Manufacturing, SMEs technology planning is important but production realisation is key factor for survival. Usually technology is not planned, if there is a need, companies will find the technological resources to fulfil orders. In large companies, either services or manufacturing, technology planning is part of their activities, however this does not mean that they are actually following a formal procedure to perform such a task.

The situation found for the technology integration and implementation, in micro companies, especially in the service sector, is not important because no special technology is needed. However in manufacturing, technology is key to the success of the company therefore a lot of effort is spent in integrating technologies and creating added value with specialised technologies (e.g. $\mathrm{CAD} / \mathrm{CAM} / \mathrm{CNC}$, laser cutting). SMEs are focusing their technologies to create added value for customers therefore they are better integrated than large companies. A lot of effort in large companies is spend in strategic and technology planning. Nevertheless, a lot of the plans for the integration and implementation of technology never are realised because the organisation structure is too complex, and usually there is a lack of leadership. Large companies usually start integration programmes supported by consulting firms in order to foresee possibilities for integration, hence technology based re-engineering is a common practice. 


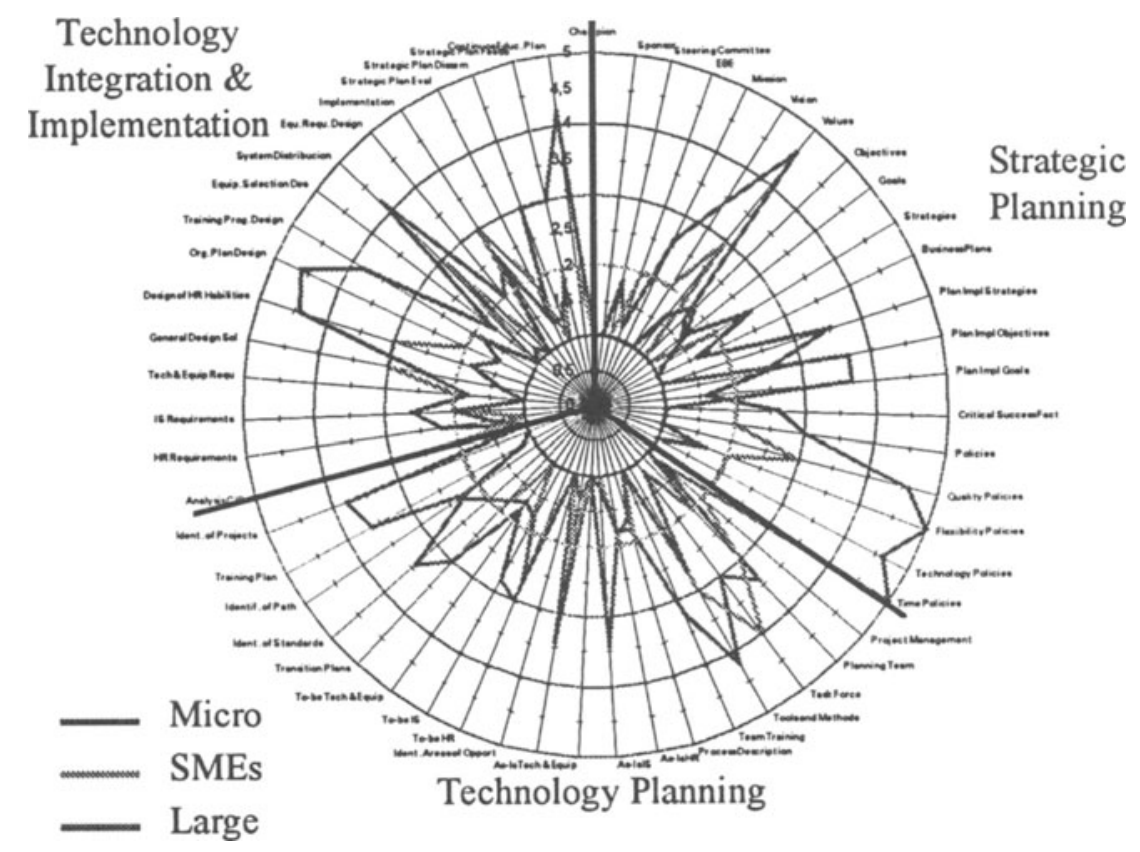

Figure 1 Opportunities in Manufacturing Companies.

\subsection{Opportunities for the Introduction of Enterprise Integration and Modeling}

Areas of opportunity were analysed using polar graphics (figures 1 and 2). The polar graphs describes major phases in the development of Enterprise Integration Programmes, for example in Strategic Planning, definitions of mission, vision, values, etc.; in Technology Planning, definition of As-Is situation or To-Be Situation; and Technology Integration, design and implementation of IT architectures, etc.

The polar graphs represent pikes where major opportunities are identified. The more concentrated to the centre of the graph the more companies are complying with ideal Enterprise Integration Programs. Important opportunities can be found in micro companies, as there is a need for strategic planning due to the absence of a formal definition of what the enterprise or business is. There is also the necessity for technology planning, as the concepts of enterprise integration are unknown. Consequently, there is no technology integration due to the lack of planning and skills to implement basic technologies. However, in micro companies there is more integration in manufacturing companies than services 


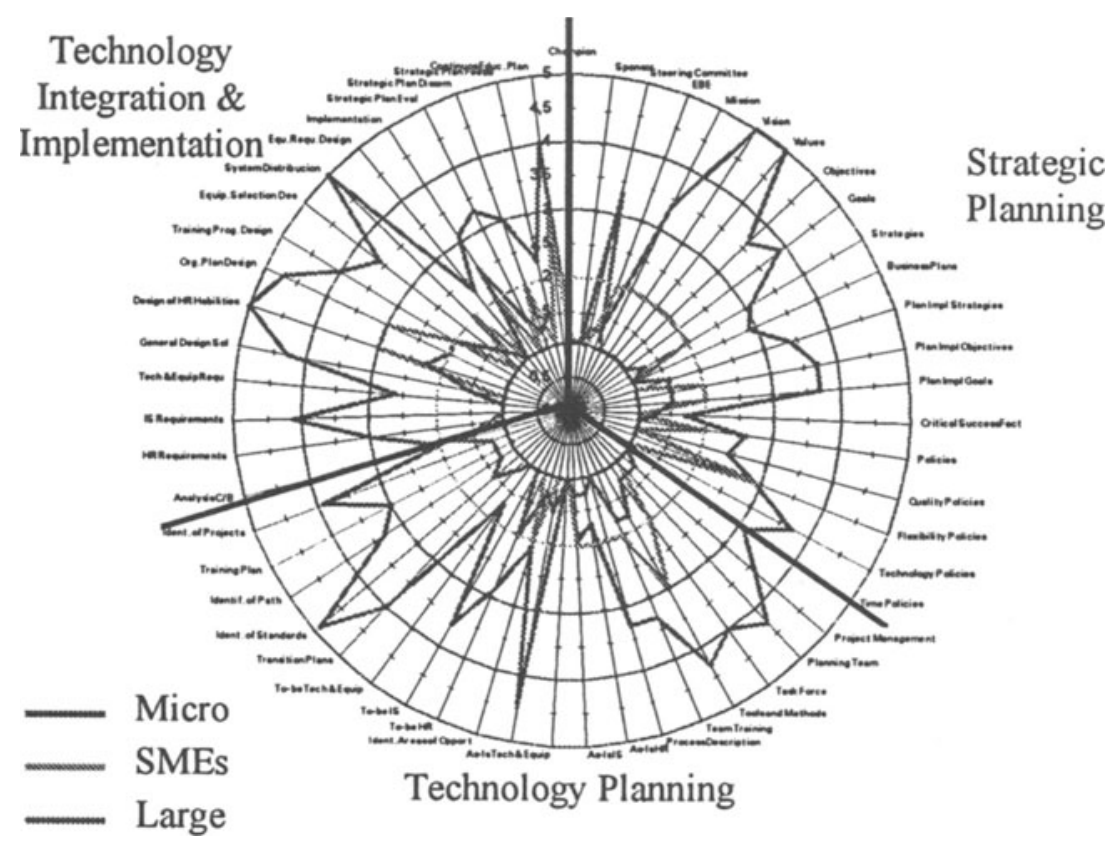

Figure 2 Opportunities for Service Companies.

companies due to the fact that there is a need to produce end-products within certain quality specification, due dates and costs.

In SMEs, there are some opportunity areas: in the strategic planning section there is a need to reinforce the business definition and its strategic plans, i.e. focus the company. Regarding technology planning, there are no formal Enterprise

Integration teams, nor formal techniques to perform technological plans. Therefore, programmes for training middle managers to develop skills for organisational planning, and EI programmes is a major issue. SMEs related to the service industry are more focused than manufacturing SMEs.

In Large companies the situation is better. Large companies usually uses the services of international consulting firms to initiate Enterprise Integration programmes. Nevertheless the problems faced by these projects and the lack of continuity. Therefore in large companies there is strategic and technology planning but there is no technology integration. Due to the high percentage of failures in these programs, large companies are looking for new IT tool (e.g. ERP systems) to achieve enterprise integration. 


\subsection{Methodologies to manage Enterprise Integration Programs}

The following sections describe different methodologies used to model business process, manage enterprise integration programmes, and manage and integrate information systems.

In micro companies the methodologies to analyse and describe the business process are:

- Flow charts

- Job instructions

- Direct observation
- Process charts

- Costs analysis

- Procedure description

There is no methodology to manage and control integration programs, the programs are carried out by engineers who have acquired expertise on the job training. In a similar way there is no use of formal methods for managing and integrating of information systems.

In addition to the methodologies, already mentioned used in micro companies, in SMEs the methodologies to analyse and describe the business process are:

- Competitive Oriented Business Plan

- Pragmatic Hermeneutics

- Elements creation and patterns generation

The methodologies used to manage and control the integration program are the creation of Task Forces with the more experienced personal using company specific methods.

The methodologies found to manage and integrate information systems are:

- Object oriented

- Out sourcing

- One Page Management

Methodologies used in large companies to analyse and describe the business process are (in addition to the one mentioned previously) :

- SADT

- Relations diagrams

- Anderson Consulting Group
- One Page System

- Boston Consulting Group

- Solution Development Design

The methodologies used by Task Forces to manage and control the integration program are: 
- Pilot Studies

- Priority Based Programs

- Anderson Consulting Group
- MicroSoft Framework

- Boston Consulting Group

- One Page System

The methodologies to manage and integrate information systems are:

- MicroSoft Framework

- Solution Development Design

- SAP

- Client-servers Architectures

- JD Edwards

From these results, we can conclude that there are no formal methods in micro companies to analyze process. Even more, our research revealed that in micro companies there are no written procedures or standards. Common methods among all companies are the ones used to analyze processes such as: flow charts, job instructions and process charts. The practice of using Task Forces in SMEs and Large companies for tackling integration problems is widely used. Companies who can afford integrated solutions are buying them from vendors for example SAP and JDEdwards.

\section{CONCLUSIONS}

There are a lot of opportunities to formalize the use of Enterprise Integration concepts in Mexican Companies, especially in Micro, Small and Medium Enterprises. These companies are an interesting target for programs in this field. Nowadays the issue of global markets and Mexican economic grown is pushing these firms to accept new concepts to improve their competitiveness. A program named IMMPAC (Acronym in Spanish for Integration and Modernization of Micro, Small and Medium Enterprises to Achieve Competitiveness) has been created to introduce the concept of Enterprise Modeling and Integration in Micro and SMEs. This project integrates training and consultancy programs to support enterprise engineering projects.

\section{REFERENCES}

Bernus P., and Nemes L., 1994, "A Framework to Define a Generic Enterprise Reference Architecture and Methodology", Task Force Meeting 9, Ottawa, Canada, August 25-26.

Williams T.J., 1991, The Purdue Enterprise Reference Architecture, Report Number 154, Purdue Laboratory for Applied Industrial Control, December. 
Arraiga A., 1996, "Análisis Situacional de la Planeación e Integración Tecnológica de Empresas a través de una Herramienta de Diagnóstico", Master Degree Thesis, ITESM, December, in Spanish

\section{BIOGRAPHY}

Dr. Arturo Molina is an Associate Professor in the Integrated Manufacturing System Center at Monterrey Institute of Technology (ITESM), Campus Monterrey, Mexico. He received his M.Sc. degree in Computer Science from ITESM, Campus Monterrey in December 1990, his University Doctor degree in Mechanical Engineering at the Technical University of Budapest in November 1992, and Phd in Manufacturing Engineering from Loughborough University of Technology in 1995 His current research interests include information systems support for concurrent engineering, information modeling, enterprise modeling and integration.

Angel Arraiga is an independent consultant in the area of Information Systems development. He received his M.Sc. degree in Information Technology Management from ITESM, Campus Monterrey in December 1996. 